\title{
Understanding climate as a driver of food insecurity in Ethiopia
}

\author{
Kirsty Lewis ${ }^{1,2}$
}

Received: 30 December 2016 / Accepted: 18 July 2017 /Published online: 10 August 2017

(C) The Author(s) 2017. This article is an open access publication

\begin{abstract}
Despite large increases in national cereal production in recent decades, Ethiopia continues to experience regular acute food insecurity crises, often associated with drought events. However, the meteorology of these events is poorly defined and local populations frequently experience food insecurity crises in years when national rainfall and cereal production totals are high. Therefore, looking at national, or even to some extent sub-national, rainfall variability is a misappropriation of climate as a causal factor in food insecurity in Ethiopia. The distinction between 'drought' as catch-all driver of food insecurity and a more nuanced view of the relationship between rainfall variability and food security is necessary both for addressing food insecurity now and for interpreting long-term climate model projections. The on-going recurrence of acute food insecurity is a feature of the heterogeneity of climate and climate variability in Ethiopia, but only in the context of a food system dominated by smallholder farming and climatesensitive livelihoods. Climate variability has the greatest adverse impact in the most marginal livelihood zones in the drier east of the country. Increasing the resilience of smallholder farmers and pastoralists to climate variability and improvements in early warning and disaster risk response could reduce the frequency and severity of food security crises. However, unless the food system in Ethiopia undergoes transformational adaptation, food insecurity crises will continue to occur, and the opportunity to achieve zero hunger by 2030 will be missed.
\end{abstract}

\section{Introduction}

Ethiopia suffers from both chronic, long-term food insecurity (WFP and CSA 2014), and the regular incidence of severe food insecurity crises, often associated with drought events (Guha-

Electronic supplementary material The online version of this article (doi:10.1007/s10584-017-2036-7) contains supplementary material, which is available to authorized users.

Kirsty Lewis

kirsty.lewis@metoffice.gov.uk

1 Met Office Hadley Centre, Exeter, UK

2 College of Life and Environmental Sciences, University of Exeter, Exeter, UK 
Sapir et al. 2015). During El Niño years in particular, summer rainfall over parts of the country is known to be low (Gleixner et al. 2016), and these years are often associated with food security crises (Glantz 1994). As the climate changes, there is concern that changes in rainfall amounts and increasing frequency and intensity of droughts will lead to Ethiopia becoming a more food insecure country (WFP 2014). Climate model projections for changes in rainfall over the Greater Horn of Africa have low confidence (Otieno and Anyah 2013), and in the absence of a clear climate change signal, adaptation to climate change has focused on building resilience to variability (For example, (BRACED 2015), (CADAPT 2015)). However, drought in Ethiopia is often defined from a socio-economic perspective, which can be as much a consequence of the food system structure, as climate itself (Devereux and Sussex 2000). The assumption that drought, in a broad sense, is a major driver of food insecurity in Ethiopia affects not only the way climate model projections are interpreted and the challenges of climate change are viewed but also the way agricultural development activity is prioritised today.

A large number of studies have been undertaken to evaluate how climate, climate variability and change could affect food security in Ethiopia (Devereux and Sussex 2000; Funk et al. 2008; Oxfam 2010; Mahoo et al. 2013; Hagos et al. 2014; WFP 2014; Jirata et al. 2016). All these reports concluded that climate variability is a causal driver of food insecurity, and therefore that climate change represents a threat to future food security. In similar studies (Deressa 2007; Ludi 2009; Arndt et al. 2011; Brown et al. 2011; Anderson and Farmer 2015), this conclusion is drawn from an understanding that water is critical to food production, and in many acute food security events, 'drought' is reported as the cause. However, in each of these studies, no formal definition of what constitutes a drought is given, so it is not necessarily clear that these 'drought' events have the same meteorological characteristics.

This lack of definition for drought is a problem, because it makes it difficult to evaluate what climate model projections mean for longer term food security outcomes. Furthermore, the reliance on anecdote also has the potential to undermine efforts to improve food security today. One example of a social study that looked at drought in Ethiopia was conducted by USAID (2000), stated that in the Ethiopian state of Amhara 'there has been no single year since 1950 where there was no drought'. From a socio-economic perspective, there is a chronic shortage of water in the region, but in meteorological terms, a drought, defined as some deficit relative to the climate average, cannot occur every year. Unpacking the socio-economic and meteorological context associated with the food security outcomes of climate in Ethiopia is key to providing salient and actionable advice on both climate variability and change, and on the action necessary to tackle food insecurity now and long term.

In this study, we compare socio-economic information about the food system and food security outcomes in Ethiopia, with the physical temporal and spatial patterns of rainfall associated with these outcomes. The aim is to address some of the interdisciplinary barriers associated with analysis across natural and physical sciences (Lewis and Lenton 2015), to test some basic assumptions about the food security-climate relationship in Ethiopia, and to provide robust evidence on that relationship to support action to tackle food insecurity at a national level.

\section{Data}

National indicators of food availability (production and yields), population and economy are available from the UN Food and Agriculture Organisation (FAO) (FAOSTAT 2014) and the World Bank (The_World_Bank 2016). These organisations in turn receive their data from 
national statistical authorities. Acute food security disasters as reported in the EMDAT database are also used (Guha-Sapir et al. 2015). Table 1 shows the list of reported droughtattributed disasters for Ethiopia since 1981. The EMDAT database contains information about disasters (rather than hazard) which are measured in terms of the impact on people. This data is rather subjective, and not reported in a standardised way, but is the best information available that records the occurrence of such events.

The climate data available for comparing with these reported events also has its limitations. The coverage of available observation sites and rain gauges for climate is poor in Ethiopia (Cattani et al. 2016; Tsidu 2012), and much of the data is available only to the National Meteorological Administration (NMA) in Ethiopia. Alternative representations of the meteorology include the use of reanalysis data (a hybrid of observational data and climate model interpolation), such as ERAInt (Balsamo et al. 2015), 20CR (Compo et al. 2011), or MERRA (Rienecker et al. 2011), satellite data, such as TRMM (Adler et al. 2016), and combined satellite and observational datasets such as CHIRPS (Funk et al. 2015). A comparison of reanalysis, satellite and CHIRPS data indicated quite large differences between the different data types, and in particular, there are some serious shortcomings in the skill of reanalysis data to represent Ethiopian climate (Sylla et al. 2013). CHIRPS data is considered by many to be the 'gold standard' of data for drought monitoring in Ethiopia and is used extensively by humanitarian agencies in the region (Boniface, R., 2016, personal communication). This data set only includes rainfall, not other variables such as temperature or evapotranspiration, which might become increasingly important as the climate warms. However, as inter-annual variability in temperature is quite low in Ethiopia, it is reasonable that the focus is on rainfall as fluctuations in this variable are the dominant driver of drought in the country. For this reason, and because it is the rainfall data of choice for food security activity in the country, CHIRPS rainfall data is used throughout this study.

\section{Food security and climate in Ethiopia}

Around $30 \%$ of the 97 million population of Ethiopia are reported as undernourished (FAOSTAT 2014). The absolute number of undernourished people has declined very little in

Table 1 Reported drought disasters for Ethiopia with $\geq 100,000$ people affected (source EMDAT (Guha-Sapir et al. 2015), WFP (2014))

\begin{tabular}{|c|c|c|c|}
\hline Dates & Location & $\begin{array}{l}\text { Total } \\
\text { deaths }\end{array}$ & $\begin{array}{l}\text { Total } \\
\text { affected }\end{array}$ \\
\hline $1983 / 1984$ & Wollo, Gondar, Goe, Eritrea, Tigray, Shoa, Haregre, Sidamo & 300,000 & $7,750,000$ \\
\hline $1987^{\mathrm{a}}$ & $\begin{array}{l}\text { Eritrea, Tigray, Ogaden, Wello, Shewa, Gama, Gofa, Sidamo, Gondar, } \\
\text { Bale }\end{array}$ & 367 & $7,000,000$ \\
\hline $1989-1994^{\mathrm{a}}$ & Northern Ethiopia, Eritrea, Tigray, Wollo, Gondar, Harerge & & $6,500,000$ \\
\hline $\begin{array}{l}1997 \\
1998^{\mathrm{a}}\end{array}$ & Oromia, Bale, Borena, South Ome, Somali & & 986,200 \\
\hline $2003^{\mathrm{a}}$ & Tigray, Oromia, Amhara, Somali, Afar & & $12,600,000$ \\
\hline $2005^{\mathrm{a}}$ & Afar, Liben, Gode zones, Somali, Borena, Somali & & $2,600,000$ \\
\hline $2008 / 2009^{\mathrm{a}}$ & Oromia, Somali, Amhara, Afar, Tigray, SNNPR & & $6,400,000$ \\
\hline $2009 / 2010$ & & & $6,300,000$ \\
\hline $2011 / 2012$ & Somali, Oromia, Afar, Tigray, Amhara & & $4,805,679$ \\
\hline $2012 / 2012$ & & & $1,000,000$ \\
\hline $2015 / 2016$ & Somali, Afar & & $10,000,000$ \\
\hline
\end{tabular}

${ }^{\text {a }}$ Some disagreement over exact dates with other sources such as Reliefweb (2016) 
the past 25 years, from 40 million in 1990 to around 35 million in 2015. Although in percentage terms, there has been a substantial decrease from the $60 \%$ level seen in the 1990s, to a figure closer to $30 \%$. By this measure, Ethiopia has met the Millennium Development Goal target to 'halve, between 1990 and 2015, the proportion of people who suffer from hunger' (UN 2000). At the same time, the incidence of reported acute food insecurity events does not seem to have fallen, and although the numbers of people killed as a result of drought-driven famine have not subsequently reached the totals seen in 1984, events that affect greater than 1 million people continue to occur frequently (Table 1).

\subsection{Rainfall variability as a driver of national food security}

One assumption made about Ethiopia is that rainfall variability is a critical driver of food insecurity nationally. The evidence for this assumption comes from a variety of studies which find an inverse correlation between GDP growth and rainfall variability (Brown and Lall 2006; Thornton et al. 2006; World Bank 2006; Grey and Sadoff 2007; Brown et al. 2011).

One study in particular that is widely cited as proof of a relationship between rainfall and food insecurity at a national scale in Ethiopia is the World Bank Water Report (WorldBank 2006). In this study, rainfall variability was plotted against GDP growth as evidence of a correlation between the two. This relationship is used to support the argument for the importance of rainfall variability to economic development, and therefore food security and other human well-being outcomes in Ethiopia in a number of studies (Thornton et al. 2006; Grey and Sadoff 2007; WFP 2014).

In their study on adaption to climate change in Ethiopia Conway and Schipper (2011) revisit this relationship, and find that if more recent data is included the correlation is far weaker. Revisiting this relationship for a second time to include the latest data, we find that the relationship between national rainfall anomaly and GDP growth rate does not recover, suggesting that the initial findings of a significant correlation do not hold. Figure 1 shows a correlation between rainfall variability (using CHIRPS rainfall data (Funk et al. 2008)) and GDP growth of 0.24 , compared with 0.40 from the original World Bank analysis (as estimated by Conway and Schipper (2011)), and 0.10 found by Conway and Schipper (2011) in their subsequent analysis. Introducing a 1-year lag does not improve the correlation.

Around $60 \%$ of the average daily calorific intake for Ethiopians comes from cereals, of which maize, sorghum, teff (a local grain indigenous to Ethiopia) and wheat are the most important (FAOSTAT 2014). Figure 2 shows annual rainfall variability and the yield and total production anomaly from the de-trended mean for these four crops. The correlation between rainfall variability and cereal production is in fact weaker than for GDP (Fig. 3), with a correlation coefficient of only 0.23 . For yield, it is weaker again at 0.15 . (For individual crops, the correlation between production and GDP is highest for maize and wheat at 0.24 and lower for sorghum at (0.18) and teff (0.1)).

From this, it is possible to conclude that national rainfall variability is not necessarily a major driver of variability in total food availability in Ethiopia, or even a good indicator of crop yield. This conclusion is supported by a more in-depth study by (Bewket 2009) which looked at the relationship between rainfall variability and crop production (rather than food security) in Ethiopia in more detail, and also found annual rainfall to be weakly correlated with cereal production. One implication from this is that large-scale climate trends may not be a useful means of assessing the impacts of weather on future food security, as it relates to production, regardless of the confidence, or otherwise, in climate change projections. 


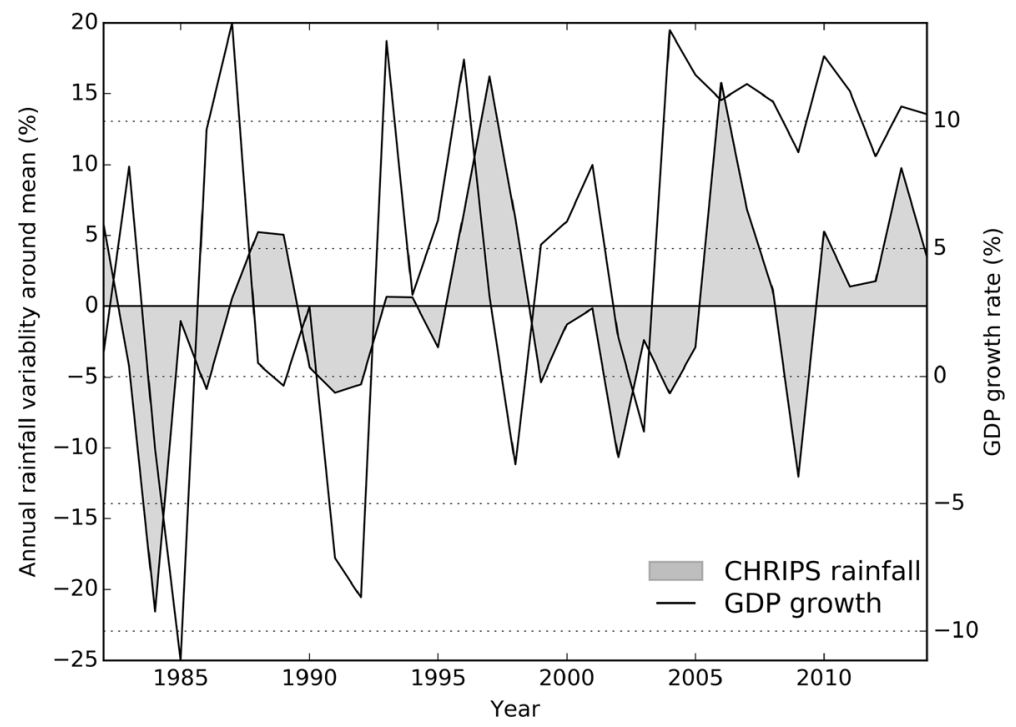

Fig. 1 Ethiopian rainfall and GDP growth rate using CHIRPS rainfall (Funk et al. 2015) data correlation $r=0.244$

\subsection{National food availability - exploring the trend}

Although production totals for all the major cereal crops have increased considerably over the past 20 years, Ethiopians' daily food calorie intake stood at 1858 as an average during 1992-

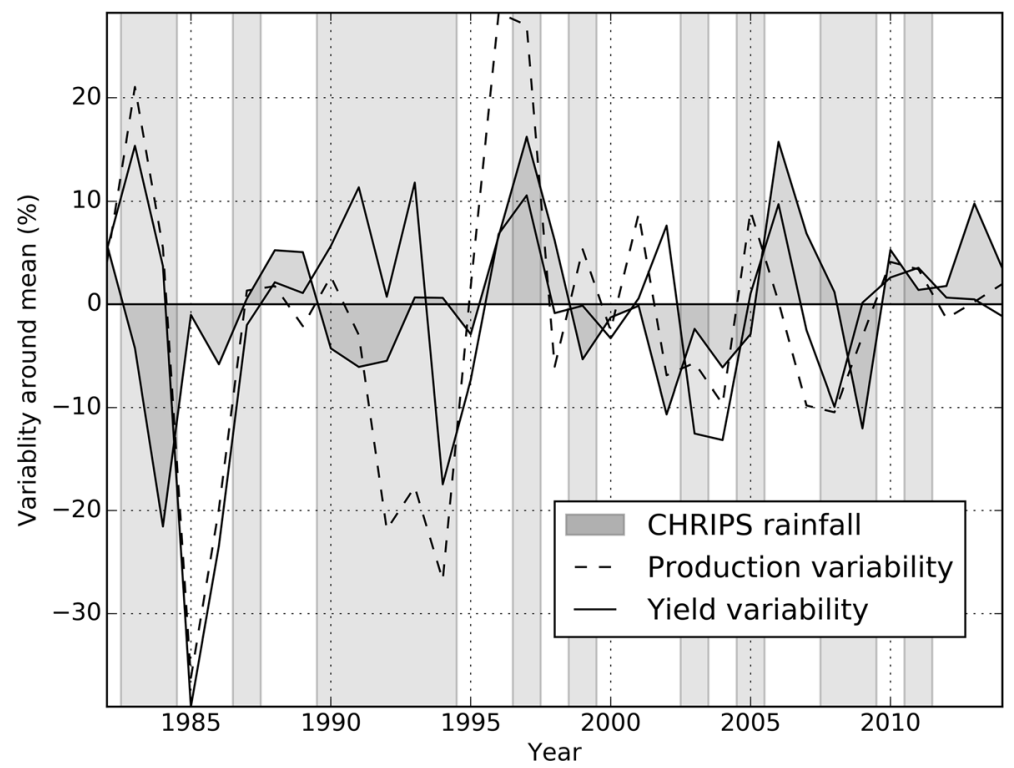

Fig. 2 Rainfall variability over Ethiopia and total cereal production (maize, sorghum, teff and wheat) anomaly relative to de-trended mean (source CHIRPS rainfall (Funk et al. 2015) FAOSTAT 2014). Reported droughtdriven food security disaster years from Table 1 are shaded in grey. Rainfall-yield variability correlation $r=0.147$. Rainfall-production variability correlation $r=0.227$ 


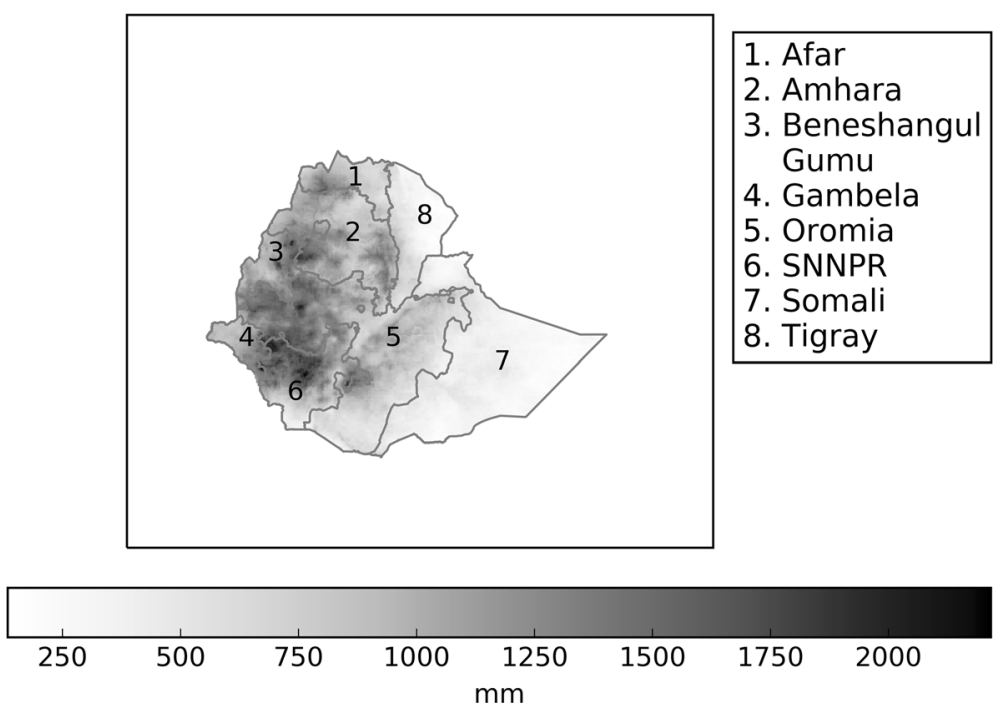

Fig. 3 Average annual precipitation over Ethiopia for 1981-2015 climatology (source CHIRPS (Funk et al. 2015))

2013 (FAOSTAT 2014); below the standard requirement of $2200 \mathrm{Kcal} / \mathrm{capita} /$ day. This means that Ethiopia does quite not produce enough food to meet a basic calorie allowance for the population as a whole.

The gap between actual yields for major cereals and the potential yield that could be achieved is high in Ethiopia. A recent study by the FAO looking specifically at wheat showed that the main producing regions achieved only between around 50 and $60 \%$ of their local attainable yields, given their altitude, weather conditions, terrain and plant health (Jirata et al. 2016). Ethiopian farming also has a very low level of technological input (low use of irrigation, specialist seed varieties, fertilisers and pesticides). Even accounting for the fact that agricultural production in Ethiopia is predominantly rain-fed, research as part of the Global Yield Gap Analysis project (Tesfaye 2015) concludes that if Ethiopia were able to halve its water-limited (i.e., rain-fed crop) yield gaps, it would be possible to produce sufficient cereals to meet the food requirement of a population of 174 million (the projected population of the county by 2050), without expanding the agricultural production area. Addressing the yield gaps in agricultural production in Ethiopia is a challenging task. It is possible that climate change will make this more difficult, but projections of average change in yield associated with future average climate are smaller than the potential gains associated with closing yield gaps, under the most climate projections (Kelbore 2012; Kassie et al. 2015). A large number of initiatives are underway to boost agricultural productivity in Ethiopia, through 'Climate-Smart' investment, that aim to reduce yield gaps and eliminate chronic food security. (For a comprehensive summary of climate-smart agriculture programmes and projects underway in Ethiopia see (Jirata et al. 2016)).

The shortfall between potential and actual production is one aspect of the problems of chronic food insecurity in Ethiopia. However, the number of food insecure has been fairly static over the same period that total production, and production per capita has increased sharply, suggesting that the benefits of increased availability are not necessarily translating into greater access for all. The fact that Ethiopia does not quite produce enough to meet the food 
requirements of the whole population does not alone explain the on-going occurrence of food security disasters in the country.

\subsection{Acute food insecurity events}

The incidence of food security disasters in Ethiopia shows little signs of decreasing over time, and the majority of these events are attributed largely to drought (Table 1) (Guha-Sapir et al. 2015). Figure 2 not only shows rainfall and cereal production variability but also includes shading to indicate periods of reported drought-driven food insecurity crises. This highlights the weak relationship between fluctuations in national cereal production and specific food security crises. This is possibly a surprising result. It indicates that while overall national production (and possibly therefore average climate suitability) is important, it is not availability of food that causes food insecurity disasters in Ethiopia. Each incidence of a food security disaster in Table 1 was recorded as an event where there was insufficient rain in an area which resulted in hunger, but there was no dip in national rainfall totals or cereal production during these events. These 'drought' incidences therefore must have been relatively local but had serious impacts on livelihoods, leaving the local populations unable to meet their food needs by buying from other regions, even though, on the whole, the country was no worse off than in any other year. This suggests that while increasing food production is being achieved, acute food insecurity is somewhat decoupled from national cereal production, possibly making it more difficult to manage successfully.

\subsubsection{Meteorology of acute food insecurity events}

Rainfall totals are highly variable across Ethiopia. Figure 3 shows the average annual precipitation over the country for the 1981-2015 climatology. The western highland areas receive the most rainfall (up to $2000 \mathrm{~mm}$ or more per year), while areas to the East and Northeast are extremely dry (receiving $250 \mathrm{~mm}$ per year or less). The majority of cereal production is concentrated in the wetter highlands, and most of the population is concentrated in these areas. Elsewhere livelihoods are predominantly pastoralist or agro-pastoralist (WFP and CSA 2014), with pastoralism concentrated in the Afar, Somali and eastern and southern Oromia regions.

Rainfall across Ethiopia is highly heterogeneous, but this is also true for rainfall anomalies. Comparing the spatial pattern of rainfall anomalies for each year in the climatological period (1981-2015) with the incidence of reported drought from Table 1 begins to unpick the reasons behind the disconnect between climate and food security at the national and sub-national level. In many years where the total annual rainfall was close to the climatological average for the country as a whole some areas experienced rainfall totals much lower than the climatological average, but higher than average totals elsewhere made up the deficit nationally (see supplementary material SM1 for rainfall distribution for individual years in the climatological record).

In every year in the period, some proportion of Ethiopia experienced rainfall $70 \%$ or less of the expected climatological average for that location (see supplementary material SM2). However, this data also shows that in every year, except one (1984), the majority of Ethiopia received at least $80 \%$ of the expected climatological average rainfall. This supports the conclusion that as a nation, Ethiopia does not have a climate adverse to food security. However, in most years, local weather conditions can cause problems for sub-national level 
food production. If livelihoods are dependent on rainfall, then in years when some regions do not receive sufficient, even if national food production totals are unaffected, these regions will be unable to access that food through the market and will experience food insecurity. Rather than this being a feature of the large-scale climate that climate models can explore, this is predominantly a feature of how food is accessed as a result of the livelihood and food system conditions in Ethiopia.

The states that are most often reported as experiencing drought are Tigray, Afar and Somali. These three states are the driest, and the states where low precipitation totals correspond most closely with periods of reported drought (Fig. 4). In the driest states, the coefficient of variability is, by definition, greater for smaller absolute changes in rainfall, meaning that in marginal dry lands even small fluctuations in absolute rainfall potentially have a large impact.

The assertion that 'every year is a drought year' (USAID 2000), while not meteorologically accurate, is a combination of the fact that somewhere in Ethiopia experiences substantially below average rainfall in almost every year, and that in some very dry parts of the country in particular, people are living on very marginal lands with highly rain sensitive livelihoods, where variability has the greatest impact.

An alternative way to show this data is given in Fig. 5a, b. This shows the number of years for which the rainfall is less than 60 or $80 \%$ of the annual average for the climatology. This is effectively a spatial projection of Fig. 4 and shows that the variability in the very driest states (Somali, Tigray and Afar) is most significant. Figure $5 \mathrm{c}, \mathrm{d}$ shows the number of years where the total rainfall fails to exceed $600 \mathrm{~mm}$ (the approximate threshold for rainfall required for the production of wheat, sorghum and teff) and $800 \mathrm{~mm}$ (the approximate threshold for rainfall

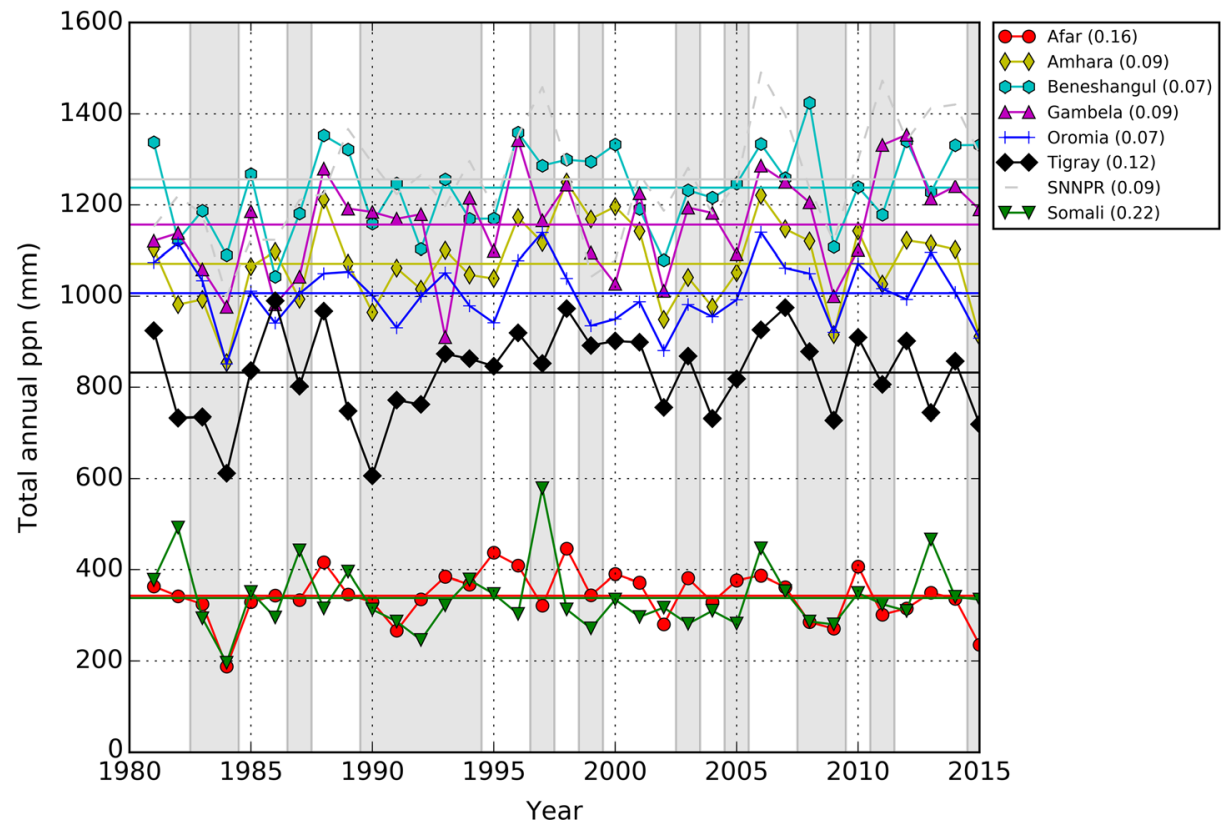

Fig. 4 Annual average rainfall over the largest Ethiopian states with coefficient of variability for each state listed periods of reported drought events from Table 1 shaded in grey (source: CHIRPS (Funk et al. 2015) \& EMDAT (Guha-Sapir et al. 2015)) 
required for the production of maize (FAO 2016)). These figures clearly show that some areas of Ethiopia have been consistently suitable for cereal production (areas in white in Fig. 5c, d), while other are not suitable at all (areas in black in Fig. 5c, d), and that only small areas of the country, on the boundary between these two regions, experience variability in total rainfall that would impact on cereal production in some years. This further reinforces the conclusion that rainfall variability is not a driver of food availability nationally. However, in those regions not suitable for cereal production, predominantly the states of Somali, Tigray and to a lesser extent Afar, where pastoralist livelihoods dominate, rainfall variability is more significant (Figs. 4 and 5).

\section{Discussion and conclusions}

Studies into food insecurity and climate in Ethiopia are often founded on the presumption that drought causes food insecurity in Ethiopia, and that by extension efforts to reduce the impact of drought through early warning mechanisms, or in the introduction of drought-resilient crops, for example, can tackle food insecurity in the country (Bryan et al. 2009; Cooper and Coe 2011). The definition of drought here is critical. Linking total rainfall to food insecurity in Ethiopia can explain some of the very large-scale events that have occurred (such as in 1984),
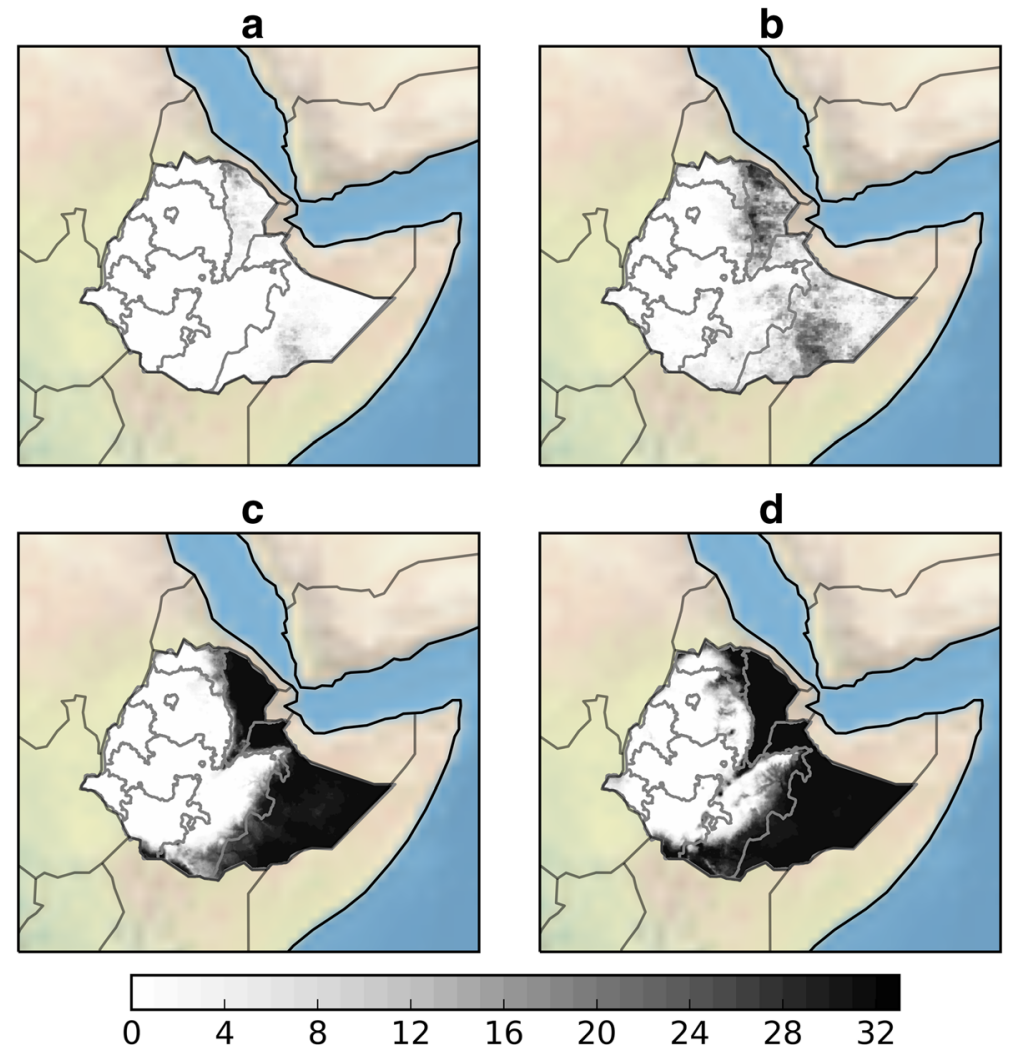

Fig. 5 Number of years in which the total annual precipitation was less that a 60 and $\mathbf{b} 80 \%$ of annual average for that location and less than c 600 and d 800 mm between 1981 and 2015 (Source CHIRPS (Funk et al. 2015)) 
but this does not explain either the chronic production shortfall that is largely the result of failure to optimise yields, or the majority of acute crises that occur much more frequently and remain a significant challenge. Although the national annual rainfall total is a poor indicator of food insecurity disasters, a localised deficit in rainfall does correspond to localised food insecurity. These events most often occur in the same years that other areas of Ethiopia have average or above average rainfall, and are therefore not associated with widespread reduction in food availability. Drought does, of course lead to crop failure, but it does not have to result in food insecurity. Food security outcomes are as much, if not more, a result of how optimised the food system as a whole is to climate than it is a function of total availability. Therefore, looking at national, or even to some extent sub-national, rainfall variability is a misappropriation of climate as the causal factor for food insecurity in Ethiopia.

Huge gains have been made in improving the national and international response to food security disasters in Ethiopia, and the fact that far fewer people now die in such events than 20 or 30 years ago is a major achievement (FAOSTAT 2014). However, if the ambition is to achieve 'zero hunger' by 2030 (UN 2015), then improving the response and resilience to disasters is not enough. It requires recognition that the means to produce enough food to meet the nutritional needs of the whole population of Ethiopia is not limited by climate, but that access to food that is affected by climate and this is a feature of the food system, not an environmental limitation.

The two key aspects of underlying systemic causes of acute food insecurity in Ethiopia are the high proportion of smallholder farmers whose livelihoods depend on sufficient rainfall, and the fact that around 14\% (CSA 2016) of the population make those climate-sensitive livelihoods on the very dry, marginal and highly variable land in the east and northeast of the country. Regardless of the levels of climate change projected for the next few decades (IPCC 2013), food insecurity could be addressed by firstly addressing the yield gaps in the most climate-suitable regions to increase national food availability, and secondly, diversifying the incomes of the approximately 13 million people in most climate-challenging regions away from agriculture. As long as these populations are dependent on local rainfall for both availability and access to food, they will continue to experience regular acute food insecurity. Action to improve resilience will reduce the frequency of these events, and improvements in early warning and disaster risk response will reduce the impact of these events, but unless there is a transformational change in the food system in these regions, food insecurity will not be eliminated.

Of course, making such substantial systemic changes is not an easy thing to achieve and are associated with political, social and cultural changes that are not trivial to implement. However, there is a danger that while working with existing systems to build resilience to climate variability through incremental adaptation could reduce the incidence and severity of acute food insecurity crises, it may also further embed communities in livelihoods that are dependent on regular humanitarian assistance to avoid catastrophe.

Climate variability, and indeed food insecurity, has always been a feature of Ethiopia, but the future threats and opportunities for the country require not simply adaptation but transformation. It is important that we fully understand the contribution of both the climate and the food system itself to national food insecurity, in order to address the unprecedented challenge of climate change and achieve the ambitious target of zero hunger by 2030 .

Open Access This article is distributed under the terms of the Creative Commons Attribution 4.0 International License (http://creativecommons.org/licenses/by/4.0/), which permits unrestricted use, distribution, and reproduction in any medium, provided you give appropriate credit to the original author(s) and the source, provide a link to the Creative Commons license, and indicate if changes were made. 


\section{References}

Adler, R., J. Awaka, et al. (2016). Tropical Rainfall Measuring Mission (TRMM). N. G. S. F. Center. Greenbelt, MD 20771 USA

Anderson S, Farmer E (2015) Food security country framework FY2016- FY 2020. USAID Office of Food for Peace: Food Economy Group, Washington DC

Arndt C, Robinson S et al (2011) Ethiopia's growth prospects in a changing climate: a stochastic general equilibrium approach. Glob Environ Chang 21(2):701-710

Balsamo G, Albergel C et al (2015) ERA-interim/land: a global land surface reanalysis data set. Hydrol Earth Syst Sci 19(1):389-407

Bewket W (2009) Rainfall variability and crop production in Ethiopia: case study in the Amhara region. In: Ege $\mathrm{S}$, Aspen H, Teferra B, Bekele S (eds) Proceedings of the 16th International Conference of Ethiopian Studies, Trondheim

BRACED. (2015) Building Resilience and adaptation to climate extremes and disasters. from http://www.braced.org/

Brown C, Lall U (2006) Water and economic development: the role of variability and a framework for resilience. Nat Res Forum 30(4):306-317

Brown C, Meeks R et al (2011) Hydroclimate risk to economic growth in sub-Saharan Africa. Clim Chang 106(4):621-647

Bryan E, Deressa TT et al (2009) Adaptation to climate change in Ethiopia and South Africa: options and constraints. Environ Sci Pol 12(4):413-426

CADAPT (2015) Climate adpatation management and innovation initiative. from http://www.wfp.org/climatechange/initiatives/c-adapt

Cattani E, Merino A, Levizzani V (2016) Evaluation of monthly satellite-derived precipitation products over East Africa. J Hydrometeor 117:2555-2573. doi:10.1175/JHM-D-15-0042.1

Compo GP, Whitaker JS et al (2011) The twentieth century reanalysis project. Q J R Meteorol Soc 137(654):1-28

Conway D, Schipper ELF (2011) Adaptation to climate change in Africa: challenges and opportunities identified from Ethiopia. Glob Environ Chang Hum Policy Dimens 21(1):227-237

Cooper PJM, Coe R (2011) Assessing and addressing climate-induced risk in sub-Saharan rainfed agriculture. Exp Agric 47(Special Issue 02):179-184

CSA (2016). Demographic and population data. C. S. A. Ethiopia

Deressa TT (2007) Measuring the economic impact of climate change on Ethiopian agriculture: Ricardian approach. Policy Research Working Paper; No. 4342. World Bank, Washington, DC. () World Bank. https://openknowledge.worldbank.org/handle/10986/7290 License: CC BY 3.0 IGO

Devereux, S. and I. Sussex (2000). Food insecurity in Ethiopia. a DFID Ethiopia Seminar, London

FAO (2016) Crop water information. http://www.fao.org/nr/water/cropinfo.html, accessed November 2016

FAOSTAT (2014) FAOSTAT online database. http://www.fao.org/faostat/en/\#home. Accessed June 2016

Funk C, Dettinger MD, Michaelsen JD, Verdin JP, Brown ME, Barlow M, Hoell A (2008) Warming of the Indian Ocean threatens eastern and southern African food security but could be mitigated by agricultural development. Proc Natl Acad Sci U S A 105(32): 11081-11086. doi:10.1073/pnas.0708196105

Funk C, Peterson P et al (2015) The climate hazards infrared precipitation with stations - a new environmental record for monitoring extremes. Scientific Data 2:150066

Glantz, H. M. (1994). Usable science: Food security, early warnings and El Nino. Proceedings of the Workshop on ENSO/FEWS

Gleixner S, Keenlyside N et al (2016) The el Niño effect on Ethiopian summer rainfall. Clim Dyn:1-19

Grey D, Sadoff CW (2007) Sink or swim?: water security for growth and development. Water Policy 9(6):545-571

Guha-Sapir D, Below R et al (2015) EM-DAT: the CRED/OFDA international disaster database. Université Catholique de Louvain, Brussels

Hagos S, Lunde $\mathrm{T}$ et al (2014) Climate change, crop production and child under nutrition in Ethiopia; a longitudinal panel study. BMC Public Health 14(1):1-9

IPCC (2013) Annex I: Atlas of Global and Regional Climate Projections [van Oldenborgh, G.J., M. Collins, J. Arblaster, J.H. Christensen, J. Marotzke, S.B. Power, M. Rummukainen and T. Zhou (eds.)]. In: Climate Change 2013: The Physical Science Basis. Contribution of Working Group I to the Fifth Assessment Report of the Intergovernmental Panel on Climate Change [Stocker, T.F., D. Qin, G.-K. Plattner, M. Tignor, S.K. Allen, J. Boschung, A. Nauels, Y. Xia, V. Bex and P.M. Midgley (eds.)]. Cambridge University Press, Cambridge and New York

Jirata M, Grey S et al (2016) Ethiopia climate-smart agriculture scoping study. FAO, Rome

Kassie BT, Asseng S et al (2015) Exploring climate change impacts and adaptation options for maize production in the central Rift Valley of Ethiopia using different climate change scenarios and crop models. Clim Chang 129(1): $145-158$ 
Kelbore, Z. G. (2012). An analysis of the impacts of climate change on crop yield and yield variability in Ethiopia. MPRA

Lewis KH, Lenton TM (2015) Knowledge problems in climate change and security research. Wiley Interdiscip Rev Clim Chang 6(4):383-399

Ludi, E. (2009). Climate change, water and food security. Background Noe, Overseas Development Institute

Mahoo, H., M. Radeny, et al. (2013). Climate change vulnerability and risk assessment of agriculture and food security in Ethiopia: which way forward? Copenhagen, Denmark, CGIAR Research Program on Climate Change, Agriculture and Food Security (CCAFS)

Otieno VO, Anyah RO (2013) CMIP5 simulated climate conditions of the greater horn of Africa (GHA). Part II: projected climate. Clim Dyn 41(7):2099-2113

Oxfam (2010) The rain doesn't come on time anymore: poverty, vulnerability, and climate variabity in Ethiopia

Reliefweb (2016) Reliefweb disasters database. http://reliefweb.int/disasters. Accessed 17 October 2016

Rienecker MM, Suarez MJ et al (2011) MERRA: NASA's modern-era retrospective analysis for research and applications. J Clim 24(14):3624-3648

Sylla MB, Giorgi F et al (2013) Uncertainties in daily rainfall over Africa: assessment of gridded observation products and evaluation of a regional climate model simulation. Int J Climatol 33(7):1805-1817

Tesfaye, K. (2015) Summary of GYGA Achivements: Ethiopia. Global Yield Gap Atlas Workshop

Thornton PK, Jones PG et al (2006) Mapping climate vulnerability and poverty in Africa. Report to the Department for International Development. ILRI, Nairobi

Tsidu GM (2012) High-resolution monthly rainfall database for Ethiopia: homogenization, reconstruction, and gridding. J Clim 25(24):8422-8443

UN (2000). United Nations Millennium Declaration. A/RES/55/2. U. G. Assembly

UN (2015) United Nations Millennium Declaration. A/RES/70/1. U. G. Assembly

USAID (2000) Amhara national regional state food security resarch assessment report. U. C. R. S. P. Team, Washington DC

WFP (2014) Climate risk and food security in Ethiopia: analysis of climate impacts on food security and livelihoods. World Food Programme, Rome

WFP and E. CSA (2014) Ethiopia-Comprehensive food security and vulnerability analysis (CFSVA), 2014

World Bank (2006) Ethiopia-managing water resources to maximize sustainable growth: water resources assistance strategy. World Bank, Washington, DC

World Bank (2016) World Bank national accounts dataset. http://databank.worldbank.org/data/home.aspx. Accessed July 2016 